attention on the part of the operator; (2) when imbedded by this method material seems to cut better, since glycerine seems to harden less than alcohol; (3) material may be stored in the concentrated glycerine if it be desirable to postpone the imbedding processes.-J. BEN HILL, Pennsylvania State College, State College, Pa.

\title{
BISPORANGIATE CONES OF LARIX
}

\section{(WITH ONE FIGURE)}

In the early spring of the present year (I9I5), in the vicinity of Missoula, Montana, abnormal cones were observed among normal

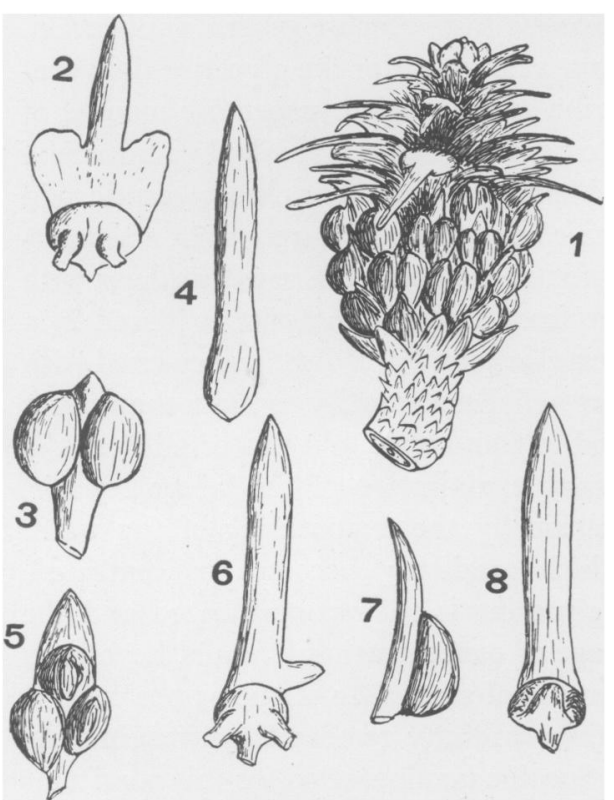

FIG. I.-Larix occidentalis: I, abnormal or bisporangiate cone, $\times 3 \frac{1}{3} ; 2$ and 3 , normal sporophylls and bract from the cone at $\mathrm{I} ; 4-8$, abnormal bracts; $2-8 \times 6 \frac{2}{3}$. ones on a single tree of Larix occidentalis. The abnormal cones were about the same size as the normal ovulate cones of the species, and consisted of two parts; the lower half of the cone presented the normal appearance of the staminate cone with the total absence of the scale, the upper half presented the typical condition of the macrostrobilus with bract and scale. The scales bore two ovules, to all external appearances normal. Between the lower and the upper portions of the cone were a few transitional structures representing abortive bracts and scales.

Some of these structures are shown in the accompanying figure. The pollen produced in the bisporangiate cone, on those sporophylls where the sporangia were apparently perfect, in its microscopic structure appeared to be the same as the pollen formed in the normal staminate cone on the same branch, except that it was somewhat smaller, measur- 
ing on an average $93 \mu$ in the diameter of the grain, as contrasted with an average of $100 \mu$ in the latter case. In the abnormal sporophylls the pollen was sometimes in lumpy masses and imperfect.

Similar cones have been described in the case of Picea, Sequoia, and Pinus, ${ }^{7}$ and have been interpreted as indicating a homology between the bract of the ovuliferous cone and the stamen, a conclusion which seems supported here.-J. E. KIRKWood, University of Montana, Missoula, Mont.

7 Coulter, John M., and Chamberlain, Charles J., Morphology of gymnosperms. Chicago. rgro. 